\title{
Knowledge, attitudes and beliefs on contributing factors among low back pain patients attending outpatient physiotherapy treatment in Malawi
}

\begin{tabular}{|c|c|}
\hline \multicolumn{2}{|c|}{$\begin{array}{l}\text { Authors: } \\
\text { Nesto Tarimo } \\
\text { Ina Diener }\end{array}$} \\
\hline \multicolumn{2}{|c|}{$\begin{array}{l}\text { Affiliations: } \\
\text { }{ }^{\text {Department of }} \\
\text { Physiotherapy, College of } \\
\text { Medicine, University of } \\
\text { Malawi, Malawi }\end{array}$} \\
\hline \multicolumn{2}{|c|}{$\begin{array}{l}{ }^{2} \text { Department of } \\
\text { Physiotherapy, University } \\
\text { of the Western Cape, } \\
\text { South Africa }\end{array}$} \\
\hline \multicolumn{2}{|c|}{$\begin{array}{l}\text { Corresponding author: } \\
\text { Nesto Tarimo, } \\
\text { tarimonesto@gmail.com }\end{array}$} \\
\hline \multicolumn{2}{|c|}{$\begin{array}{l}\text { Dates: } \\
\text { Received: } 17 \text { May } 2017 \\
\text { Accepted: } 18 \text { Sept. } 2017 \\
\text { Published: } 31 \text { Oct. } 2017\end{array}$} \\
\hline \multicolumn{2}{|c|}{$\begin{array}{l}\text { How to cite this article: } \\
\text { Tarimo, N. \& Diener, I., 2017, } \\
\text { 'Knowledge, attitudes and } \\
\text { beliefs on contributing } \\
\text { factors among low back pain } \\
\text { patients attending outpatient } \\
\text { physiotherapy treatment in } \\
\text { Malawi', South African } \\
\text { Journal of Physiotherapy } \\
\text { 73(1), a395. https://doi. } \\
\text { org/10.4102/sajp.v73i1.395 }\end{array}$} \\
\hline \multicolumn{2}{|c|}{$\begin{array}{l}\text { Copyright: } \\
\text { (c) 2017. The Authors. } \\
\text { Licensee: AOSIS. This work } \\
\text { is licensed under the } \\
\text { Creative Commons } \\
\text { Attribution License. }\end{array}$} \\
\hline \multicolumn{2}{|l|}{ Read online: } \\
\hline 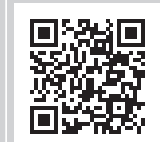 & $\begin{array}{l}\text { Scan this QR } \\
\text { code with your } \\
\text { smart phone or } \\
\text { mobile device } \\
\text { to read online. }\end{array}$ \\
\hline
\end{tabular}

Background: Low back pain (LBP) affects many people globally. Its aetiology is not clear. Patients lack knowledge of its contributing factors and have negative perception about their LBP. This study aimed to identify knowledge, attitudes and beliefs regarding the perceived contributing factors to LBP among patients attending physiotherapy outpatient departments in Malawi. This information can possibly facilitate planning of a LBP education programme in Malawi.

Methods: A quantitative cross-sectional survey was conducted, using a six-part selfadministered questionnaire with questions on demographic information, participants' attitudes and beliefs regarding their LBP, knowledge about the course and causes of LBP, beliefs regarding nine contributing factors to LBP (identified in a Delphi study) and the sources of the participants' knowledge. Data were analysed descriptively using the Statistical Package for Social Sciences (version 19.0). A Chi-square test was used to determine any association between variables (alpha 0.05). All ethical procedures were strictly followed.

Results: Most participants $(186,91.2 \%)$ did not manage to answer all six questions regarding knowledge correctly and were regarded as 'partially knowledgeable' about the course and causes of LBP. More than half (67\%) portrayed negative attitudes and beliefs about LBP in general. The findings also showed a statistically significant relationship between knowledge, attitudes and beliefs $(p=0.04)$.

Conclusion: This study highlighted that many patients with LBP in Malawi are not adequately knowledgeable about LBP and hold negative attitudes and beliefs regarding their LBP. Therefore, LBP management programmes in Malawi should include education programmes aimed at empowering patients with knowledge regarding LBP, as well as changing their negative attitudes and beliefs about their pain. Patients' understanding of the cause and nature of their pain may enhance the achievement of treatment goals.

\section{Introduction}

Low back pain (LBP) has been reported as a worldwide health problem, affecting individuals physically, socio-economically and psychologically (Hoy et al. 2012; Manchikanti et al. 2014). Although most epidemiological studies on the prevalence of LBP have been conducted in developed countries (Bruce et al. 2004; Ghaffari et al. 2006), there is not much difference between the prevalence of LBP in developed and developing countries (Louw, Morris \& Grimmer 2007). In developed countries, the lifetime prevalence is between $60 \%$ and $70 \%$ (WHO 2004). In Africa alone, it ranges between $28 \%$ and $74 \%$ and is most likely to increase globally in the next few years (Hoy et al. 2012; Louw et al. 2007).

The exact causes of LBP are often difficult to identify, and both clinicians and patients are left with uncertainties, leading to varied broad practices in the choice of management of LBP (Adam 2009; Cole \& Grimshaw 2003). In addition, most patients living with LBP lack knowledge regarding causes and contributing factors of LBP (Ng'uurah \& Frantz 2006). This is despite various treatment guidelines for LBP proposing that besides physical treatment and exercises, advice and health education should be part of the treatment plan (Koes, Van Tulder \& Thomas 2006). Health education will not only enhance peoples' knowledge about pain, but might also change their negative attitudes and beliefs regarding their pain, and thereby promote the achievement of the desired clinical outcomes (Henrotin et al. 2006). This in turn may decrease the number of patients living with acute LBP and transitioning to living with chronic LBP (Fowler \& Dabco 2004). More recently, pain neuroscience education has demonstrated good results in the management of 
LBP populations, changing pain cognitions and improving activity performance among patients (Clarke, Ryan \& Martin 2011; Louw et al. 2011; Ryan et al. 2010).

The general public, including patients living with LBP, lack knowledge about the causes and contributing factors of LBP (Allock, Elkan \& Williams 2007; Ng'uurah \& Frantz 2006; Tavafian et al. 2004). This implies that during management of LBP, patients' knowledge, attitudes and beliefs about their pain should be identified and followed by education regarding their pain. In Malawi, LBP is one of the leading musculoskeletal conditions treated at hospital physiotherapy outpatients' departments. However, no information is available regarding patients' knowledge, attitudes and beliefs regarding their LBP. This study thus aimed to establish the knowledge (understanding), attitudes and beliefs regarding perceived contributing factors to LBP among patients seeking physiotherapy management for their LBP at health centres in Malawi.

\section{Methods and materials}

This study was conducted in the physiotherapy outpatient departments of Queen Elizabeth and Kamuzu Central hospitals in Malawi. A quantitative research design using a cross-sectional survey was used. Convenience sampling was used as the recruitment method with a self-administered questionnaire for data collection. The questionnaire consisted of six sections. In the first two sections, demographic and social data as well as information on the current state of participants' LBP was gathered. The third section, on the attitudes and beliefs regarding LBP, was based on the Back Beliefs Questionnaire (Symonds et al. 1996) and the Survey of Pain Attitude Questionnaire (Jensen et al. 1994). The fourth section, based on pertinent literature and the LBP Knowledge Questionnaire (Maciel et al. 2009), sought participants' knowledge and understanding of the course and causes of LBP in general. The fifth section of the questionnaire explored participants' beliefs regarding nine contributing factors to LBP. Firstly, a literature review was conducted to identify the contributing factors to LBP. Fifteen contributing factors were identified (Table 1). A Delphi method was then used to establish the most important contributing factors to LBP by seeking the opinion from a panel of experts (physiotherapists with more than 2 years of experience in the field of LBP). Twenty experts were identified and 15 agreed to participate. The Delphi method included three rounds (Custer, Scarcella $\&$ Stewart 1999). In the first round, the 15 contributing factors were sent to the experts and they were requested to add any other contributing factors. After the first round, a new list of 38 factors was compiled, which included the factors added by the experts (Table 2). In the second and third rounds, the experts were asked to rate the 38 factors on a four-point Likert scale ranging from $1=$ 'not important' to $4=$ 'very important'. Seventy per cent or higher agreement on an element was interpreted as an acceptable level of consensus (Hsu \& Standford 2007). Factors rating 30\% or less were eliminated from the list. All factors (nine in total) that were ranked $70 \%$ and above were identified and included
TABLE 1: List of causing or contributing factors to low back pain from a review of the literature.

\begin{tabular}{ll}
\hline No. & Contributing factors \\
\hline 1. & Analgesic dependency \\
2. & Anxiety \\
3. & Depression \\
4. & $\begin{array}{l}\text { Fear avoidance beliefs (Fear that movement may injure structures in } \\
\text { the back) }\end{array}$ \\
5. & $\quad$ Flexion combined with compressive force to the lumbar spine (e.g. in \\
& lifting heavy objects) \\
6. & $\begin{array}{l}\text { Frequency of twisting and bending of the spine during work of sport } \\
\text { 7. }\end{array} \quad$ Obesity \\
\hline 8. & Physically demanding work (as perceived by the patient) \\
9. & Poor or unhappy social environment at work \\
10. & Prolonged sitting (more than 30 min) \\
\hline 11. & Repetitive heavy lifting \\
12. & Smoking \\
13. & Social psychological stress and events in life \\
14. & Stressful life events (e.g. caring for the sick or facing death) \\
15. & Whole-body vibration (e.g. in truck driving and other work activities) \\
\hline
\end{tabular}

Source: Authors' own work

TABLE 2: List of causing or contributing factors to low back pain after round 1 of the Delphi study.

\begin{tabular}{|c|c|}
\hline No. & Contributing factors \\
\hline 1. & Age \\
\hline 2. & Analgesic dependency \\
\hline 3. & Anxiety \\
\hline 4. & Catastrophising \\
\hline 5. & Co-morbid diseases (e.g. diabetes, hypertension, cardiac pathology) \\
\hline 6. & Compensation situations (e.g. work injuries, third part) \\
\hline 7. & Congenital malformations (e.g. loss of lumbar curvature) \\
\hline 8. & Degenerative joint disease from old age \\
\hline 9. & Depression \\
\hline 10. & Fear avoidance beliefs (fear that movement may injure structures in the back) \\
\hline 11. & $\begin{array}{l}\text { Flexion combined with compressive force to the lumbar spine (e.g. in } \\
\text { lifting heavy objects) }\end{array}$ \\
\hline 12. & Frequency of twisting and bending of the spine during work of sport activities \\
\hline 13. & Gender \\
\hline 14. & Leg length discrepancy \\
\hline 15. & Obesity \\
\hline 16. & Passive coping \\
\hline 17. & Patient's lack of understanding of pathology \\
\hline 18. & Perceived future problems \\
\hline 19. & Perception on workload \\
\hline 20. & Physically demanding work, as perceived by the patient \\
\hline 21. & Poor mattress quality \\
\hline 22. & Poor or unhappy social environment at work \\
\hline 23. & Posture \\
\hline 24. & Pregnancy \\
\hline 25. & Previous epidural anaesthetic spinal block \\
\hline 26. & History of back pain \\
\hline 27. & Prolonged sitting (more than $30 \mathrm{~min}$ ) \\
\hline 28. & Repetitive heavy lifting \\
\hline 29. & Self-efficacy beliefs \\
\hline 30. & Smoking \\
\hline 31. & Social psychological stress and events in life \\
\hline 32. & Some sport activities (e.g. skiing ) \\
\hline 33. & Spouse relations - a solicitous spouse may increase pain behaviour \\
\hline 34. & Stressful life events (e.g. caring for the sick or facing death) \\
\hline 35. & Trauma or injury \\
\hline 36. & Trigger points in gluteus muscles \\
\hline 37. & Types of the chair used at home or work \\
\hline 38. & Whole-body vibration (e.g. in truck driving and other work activities) \\
\hline
\end{tabular}


in the questionnaire (Table 3). The last section of the questionnaire identified the sources of the participants' knowledge and their views on their own LBP. The developed questionnaire was tested in a pilot study to determine the user-friendliness, the clarity of the instrument as well as time to complete the questionnaire (De Vos 2002). Ten patients with LBP participated in the pilot study and they were excluded from the main study. The pilot study revealed that a few questions were slightly unclear to the participants, because of the use of medical terminologies. The questions were revised and the modifications to those medical terms were made by replacing them with simple terms (Table 4 ).

\section{Ethical consideration}

Ethical clearance was obtained from the University of the Western Cape and the College of Medicine in Malawi with certificate numbers 10/9/22 and P.10/10/1005, respectively. Participants were informed regarding the study before participation and all participants signed informed consent.

\section{Results}

\section{Socio demographic characteristics}

Two hundred and five participants were recruited, of whom $109(53 \%)$ were women, with a mean age of $47.74( \pm 13.29)$ years. Table 5 illustrates the socio demographic characteristics of the study sample.

\section{Low back pain frequency and duration}

The majority of the participants 99 (48.3\%) reported that the pain was continuous, while 81 participants $(39.5 \%)$ indicated that the LBP was episodic, and only 25 participants (12.2\%) reported a first-time (or once-off) episode of LBP.

TABLE 3: Highest ranked contributing factors to low back pain (Delphi study, $n=15$ ).

\begin{tabular}{lcc}
\hline Contributing factor & \multicolumn{2}{c}{ Frequency } \\
\cline { 2 - 3 } & $\boldsymbol{n}$ & $\%$ \\
\hline $\begin{array}{l}\text { 1. Compensation situations } \\
\text { (e.g. injuries at work places) }\end{array}$ & 11 & 73.3 \\
2. Physically demanding works & 12 & 80.0 \\
$\begin{array}{l}\text { 3. Trauma or injury at the back } \\
\text { 4. Whole-body vibration }\end{array}$ & 12 & 80.0 \\
$\begin{array}{l}\text { 5. Fear avoidance beliefs } \\
\text { 6. History of back pain }\end{array}$ & 12 & 80.0 \\
$\begin{array}{l}\text { 7. Twisting and bending of } \\
\text { the spine }\end{array}$ & 13 & 86.7 \\
8. Flexion combined with \\
compressive forces
\end{tabular}

Source: Authors' own work

TABLE 4: The simplified terms from the Pilot study.

\begin{tabular}{llll}
\hline $\begin{array}{l}\text { Section in the } \\
\text { questionnaire }\end{array}$ & Question No. & Term & Changed to \\
\hline A-2 & 1 & Episodic & $\begin{array}{l}\text { Intermittent: comes } \\
\text { and goes }\end{array}$ \\
B-2 & 2(b) & Athrosis & $\begin{array}{l}\text { Joint problems } \\
\text { Slipped disc }\end{array}$ \\
\hline
\end{tabular}

Source: Authors' own work
Seventy-eight per cent of all participants reported LBP for more than 6 months, followed by 21 (10.2\%) who reported LBP for 2-3 months and 24 (11.8\%) reported pain for 1 month or less.

\section{Attitudes and beliefs about their own low back pain}

Twelve statements were provided in the questionnaire (Table 6), requiring participants to indicate from strongly disagree to strongly agree, their opinion regarding their own LBP. The majority of the participants, 190 (93\%), reported fear of movement and activity avoidance because of their LBP, while 147 (72\%) believed that their LBP eventually would prevent them from working and would remain with them for the rest of their lives. Thirty-three per cent of all participants demonstrated positive attitudes and beliefs on all statements but the majority of participants, $137(66.8 \%)$, demonstrated negative attitudes and beliefs regarding their LBP.

\section{Knowledge of the participants about the course and causes of low back pain}

Participants were given a series of six questions to indicate their choices on the factors that possibly cause LBP (Table 7). The majority of the participants, 186 (91.2\%), were partially knowledgeable on the course and causes of LBP in general. Only $18(8.8 \%)$ of them answered all questions correctly and were considered to be fully knowledgeable on the course and causes of LBP. Table 8 summarises the participants' knowledge on causes and contributing risk factors to LBP.

TABLE 5: Socio demographic characteristics of the study sample $(n=205)$.

\begin{tabular}{|c|c|c|}
\hline Variable & Frequency $(n)$ & $(\%)$ \\
\hline \multicolumn{3}{|l|}{ Gender } \\
\hline Males & 96 & 46.8 \\
\hline Females & 109 & 53.2 \\
\hline \multicolumn{3}{|l|}{ Age group } \\
\hline $15-24$ years & 8 & 3.9 \\
\hline $25-34$ years & 27 & 13.2 \\
\hline $35-44$ years & 44 & 21.5 \\
\hline $45-54$ years & 62 & 30.2 \\
\hline $55-64$ years & 43 & 21.0 \\
\hline$\geq 65$ years & 21 & 10.2 \\
\hline \multicolumn{3}{|l|}{ Level of education } \\
\hline Never attended school & 66 & 32.0 \\
\hline Primary level & 98 & 47.8 \\
\hline Secondary level & 34 & 16.6 \\
\hline Tertiary level & 7 & 3.4 \\
\hline \multicolumn{3}{|l|}{ Marital status } \\
\hline Single & 48 & 23.4 \\
\hline Married & 104 & 50.7 \\
\hline Divorced & 19 & 9.3 \\
\hline Separated & 3 & 1.5 \\
\hline Widow & 25 & 12.2 \\
\hline Widower & 6 & 2.9 \\
\hline \multicolumn{3}{|l|}{ Residential area } \\
\hline Rural & 47 & 22.9 \\
\hline Urban & 158 & 77.1 \\
\hline
\end{tabular}

Source: Authors' own work

Mean age 47.74 years $(S D=13.29$ ). 
TABLE 6: Summary of responses of participants on attitudes and beliefs regarding their own low back pain.

\begin{tabular}{|c|c|c|c|}
\hline Statements & Agree & Do not know & Disagree \\
\hline 1. People with LBP should avoid movement as it may cause more injury & $190(92.7 \%)$ & $5(2.4 \%)$ & $10(4.9 \%)$ \\
\hline 2. Pain acceptance facilitates recovery from LBP & $111(54.1 \%)$ & $36(17.6 \%)$ & $58(28.3 \%)$ \\
\hline 3. Only health personnel can cure LBP & $175(85.4 \%)$ & $9(4.4 \%)$ & $21(10.2 \%)$ \\
\hline 4. Self-management on your LBP has no effect on recovery & $82(40.0 \%)$ & $49(23.9 \%)$ & $74(36.1 \%)$ \\
\hline 5. LBP will eventually stop you from working & $147(71.7 \%)$ & $22(10.7 \%)$ & $36(17.6 \%)$ \\
\hline 6. Your LBP will last with you for the rest of your life & $26(12.7 \%)$ & $83(40.5 \%)$ & $96(46.8 \%)$ \\
\hline 7. LBP will never stop you doing what you really want to do & $85(41.5 \% 0$ & $28(13.7 \%)$ & $92(44.8 \%)$ \\
\hline 9. Having LBP may mean you will end up with disability & $55(26.8 \%)$ & $53(25.9 \%)$ & $97(47.3 \%)$ \\
\hline 10. You can control the amount of pain you feel by changing your thoughts & $64(31.2 \%)$ & $66(32.2 \%)$ & $75(36.6 \%)$ \\
\hline 11. To know more about your pain, the best way is to go to the healthcare facility & $191(93.2 \%)$ & $6(2.9 \%)$ & $8(3.9 \%)$ \\
\hline 12. LBP gets progressively worse later in life & $143(69.8 \%)$ & $39(19.0 \%)$ & $23(11.2 \%)$ \\
\hline
\end{tabular}

Source: Authors' own work

For clarity, the responses 'strongly agree' and 'agree' were collapsed into 'agree' and the responses 'strongly disagree' and 'disagree' were collapsed into 'disagree'.

LBP, low back pain.

TABLE 7: Participants' agreement on individual statements regarding the course and causes of low back pain.

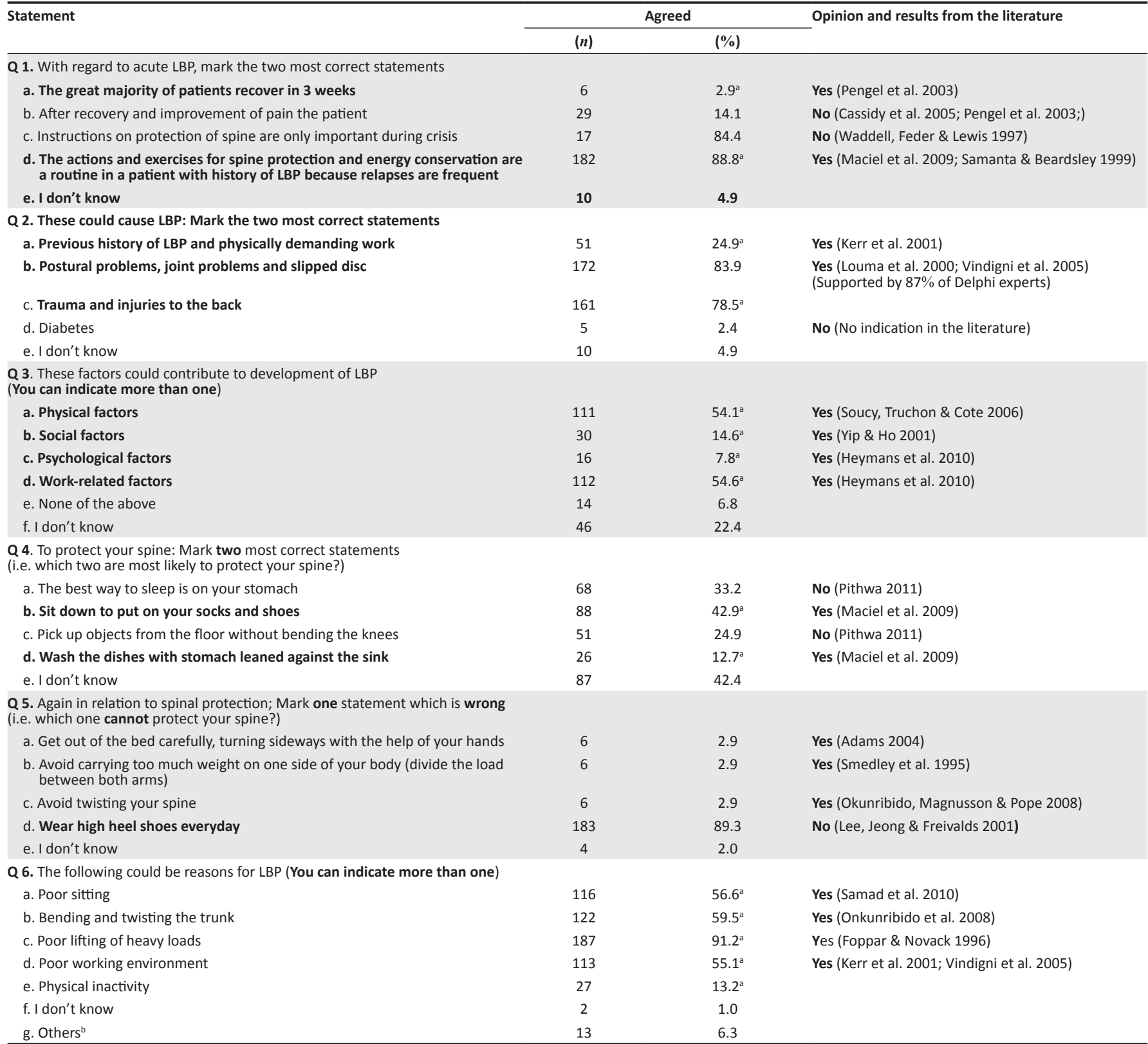

Source: Authors' own work

LBP, low back pain.

a, The correct statement(s) based on the literature.

b, Includes mismanagement during child birth, climbing mountain, prolonged standing and poor mattress. 
TABLE 8: Summary of the participants' knowledge on the course and causes of low back pain.

\begin{tabular}{|c|c|c|}
\hline \multirow[t]{2}{*}{ Portrayed knowledge per individual question } & \multicolumn{2}{|c|}{ Frequency } \\
\hline & $(n)$ & $(\%)$ \\
\hline \multicolumn{3}{|c|}{ Q 1. Choices of the participants with regards to acute LBP } \\
\hline All chosen statements are wrong & 22 & 10.7 \\
\hline Only one correct statement chosen & 178 & 86.8 \\
\hline Both the statements correctly chosen & 5 & 2.4 \\
\hline \multicolumn{3}{|c|}{ Q 2. Choices of the participants with regard to causes of LBP } \\
\hline All chosen statements are wrong & 14 & 6.8 \\
\hline Only one correct statement chosen & 171 & 83.4 \\
\hline Both the correct statements chosen & 20 & 9.8 \\
\hline \multicolumn{3}{|l|}{$\begin{array}{l}\text { Q 3. Choices of the participants with regard } \\
\text { to factors contributing to LBP }\end{array}$} \\
\hline All chosen statements are wrong & 60 & 29.3 \\
\hline Only one correct statement chosen & 45 & 22.0 \\
\hline Only two correct statements chosen & 83 & 40.5 \\
\hline Only three correct statements chosen & 12 & 5.9 \\
\hline All four statements correctly chosen & 5 & 2.4 \\
\hline \multicolumn{3}{|c|}{ Q 4. Choices of the participants with regard to spine protection } \\
\hline All chosen statements are wrong & 106 & 51.7 \\
\hline Only one correct statement chosen & 83 & 40.5 \\
\hline Both the statements correctly chosen & 16 & 7.8 \\
\hline \multicolumn{3}{|l|}{$\begin{array}{l}\text { Q 5. Choices of the participants in relation to spine } \\
\text { protection again }\end{array}$} \\
\hline Wrong statements & 22 & 10.7 \\
\hline Correct statement & 183 & 89.3 \\
\hline \multicolumn{3}{|c|}{ Q 6. Choices of the participants on the possible reasons for LBP } \\
\hline All chosen statements are wrong & 2 & 1.0 \\
\hline Only one correct statement chosen & 4 & 2.0 \\
\hline Only two correct statements chosen & 85 & 41.5 \\
\hline Only three correct statements chosen & 60 & 29.3 \\
\hline Only four correct statements chosen & 47 & 22.9 \\
\hline All five correct statements correctly chosen & 7 & 3.4 \\
\hline
\end{tabular}

Source: Authors' own work

LBP, low back pain.

\section{Attitudes and beliefs of contributing factors to their low back pain}

The minimum level of consensus during the Delphi study was set at $70 \%$. Nine contributing factors were ranked high by the experts and therefore included in the questionnaire of this study. Patients living with LBP were then requested to indicate their opinions regarding these nine factors, with the responses ranging from strongly disagree to strongly agree. The majority $(86.3 \%)$ of the participants living with LBP agreed that all nine factors could contribute to the development and/or worsening of their LBP.

\section{Sources of participants' knowledge of low back pain}

The results demonstrated that more than half, 114 (55.6\%), of the participants received information regarding their LBP from various sources, including medical officers, physiotherapists, books, Internet, media and schools. The predominant sources of information were medical officers, 38 (33.3\%), and physiotherapists, 35 (30.7\%). The information obtained was on self-care and the importance of exercises. Less than $1 \%$ received information only on contributing factors. Overall, 66 (57.9\%) of the participants indicated that the information they received was completely understood by them, while $84(73.7 \%)$ acknowledged that the information was useful to manage their LBP. A chi-squire test revealed a significant relationship between knowledge, attitudes and beliefs of the participants $(p=0.04)$.

\section{Discussion}

\section{Socio demographic characteristics and low back pain status of participants}

The majority of the patients with LBP attending hospital physiotherapy outpatient departments in Malawi were middle-aged women, married, living in an urban area and had a primary level of education. Several population-based studies conducted in both Western and African countries reveal that women are more affected by LBP than men (Sikiru \& Hanifa 2010). The female dominance in reported LBP could be because of the fact that women are more likely to seek healthcare for their pain than men and that women may have lower pain thresholds than men (Seotanto, Chung \& Wong 2006). Almost half of the participants in our study reported living with chronic recurrent LBP.

\section{Knowledge of low back pain}

Patients with LBP tend to seek information regarding their pain from diverse sources. More than $50 \%$ of the participants reported having received information regarding their LBP from medical officers and physiotherapists. The information received included self-care and the importance of exercises for their LBP. Less than $1 \%$ received information on the contributing factors for LBP. This was also the case in the study by Tavafian et al. (2004). However, Ng'uurah and Frantz (2006) found that the main reasons for patients seeking healthcare are because of their pain experience as well as because of understanding the causes and available remedies for their pain ( $\mathrm{Ng}^{\prime}$ uurah \& Frantz 2006). It is well known that patients rely on healthcare providers to understand the causes as well as to educate and advise them on possible management of their health problems (Foster et al. 2003). Therefore, Ng'uurah and Frantz (2006) advised that in order to avoid patients' misconceptions regarding their LBP, the information should be given in a form that patients can easily understand.

It is therefore essential for healthcare providers and other individuals who are involved in managing patients with LBP to identify the needs and the reasons for patients seeking health services (Nasser 2005). In the management of recurrent LBP, patients' knowledge regarding the source and mechanism of the pain is important in achieving better treatment outcomes (Ng'uurah \& Frantz 2006; Tavafian et al. 2004).Our study results demonstrate that the majority of participants were partially knowledgeable on the course and causes of LBP. Ng'uurah and Frantz (2006) in their study conducted in Kenya also concluded that the majority of patients lacked knowledge regarding the causes and contributing factors for LBP. Similarly, Allock et al. (2007) and Mwilila (2008) found that the majority of patients did not understand the cause of their pain, and the main reason for them visiting healthcare providers was to be educated on the cause of their pain and to 
seek reassurance regarding the diagnosis and the role of the medication prescribed for their problem. Health education regarding patient's LBP should be included in the management programme of LBP. Tugwell et al. (2007) proposed that although patients are the experts of their experience of their own illness, they still need to be educated about their illness and its possible causes to enable them to make their own decisions regarding their health. Education has long been used in order to alleviate pain and reduce disability associated with LBP (Udermann et al. 2004). Many studies have examined the effect of education on pain and disability and reported excellent outcomes. The results show that the introduction of an individualised educational booklet on back biomechanics may result in decreased pain and frequency of LBP episodes in patients living with chronic LBP (Coudeyre et al. 2007; Dupeyron et al. 2011; Udermann et al. 2004).

Recent studies evaluated the use of neuroscience education in decreasing pain and disability among patients with LBP (Louw, Nijs \& Puentedura 2017). Neuroscience education focuses on neurophysiology and the processing of pain (Louw et al. 2017). Studies that utilise neuroscience education have been shown to decrease fear and change patients' perception of their pain (Meeus et al. 2010; Ryan et al. 2010). Providing patients with education on pain physiology assists in reconceptualising the concept of pain, enhances the patient's understanding of their chronic pain and limits the development of inappropriate pain cognitions and negative beliefs (Meeus et al. 2010). Furthermore, it decreases the fear of re-injury among patients, thus enhancing their physical performances (Ryan et al. 2010). A systematic review provided strong evidence for education on pain neuroscience, addressing pain, disability and physical performance in musculoskeletal pain, particularly spinal disorders (Louw et al. 2011). It is therefore clear that the available literature indicates that pain neurophysiology education should be included as part of the management of LBP.

\section{Attitudes and beliefs regarding low back pain}

Ascertaining the attitudes and beliefs patients may hold regarding their pain could facilitate the management of their pain (May 2007). The continuous fostering of negative attitudes and beliefs among patients living with LBP may hinder the achievement of the desired treatment outcomes (Symonds et al. 1996). This implies that changing attitudes and beliefs through education regarding the source and contributing factors to patients' pain could speed up recovery and enhance earlier return to functional activities (May 2007). The majority of participants in our study indicated negative attitudes and beliefs regarding their own LBP. Participants reported fear of movements and activity avoidance. Threequarters of the participants believed that their LBP would eventually prevent them from working and that it would remain for the rest of their lives. Darlow et al. (2014) found that the majority of patients believed that movements and physical activity could cause more harm to their LBP, resulting in avoiding certain activities. Hanney, Kolber and Beekhuizein (2008) and Linton, Vlaeyen and Ostelo
(2002) indicated that negative beliefs among patients living with LBP may aggravate their pain, leading to functional limitations and chronic pain patterns. It is therefore important, during management of LBP, that patients' misconceptions regarding their pain be identified and addressed (Darlow et al. 2014).

LBP could occur as a result of many contributing factors and the debate in the literature regarding the exact causes or contributing factors to the occurrence of LBP is still inconclusive. However, both physical and psychosocial factors have been indicated as contributing factors to LBP (George et al. 2006; Heymans et al. 2010; Soucy et al. 2006). The majority of our participants strongly believed that all nine factors (identified in the Delphi study) could contribute to the development or maintenance of their LBP. Our participants strongly believed that factors including repetitive heavy lifting, physically demanding jobs, frequent twisting and bending of the spine and flexion combined with compressive forces to the lumbar spine, fear avoidance beliefs, injury to the back and previous history of LBP could contribute to the occurrence of LBP. Samad et al. (2010) found that factors such as repetitive heavy lifting, prolonged sitting and prolonged flexing of the spine were also indicated as potentially contributing to the occurrence of LBP. Fear avoidance beliefs and somatisation (feeling sick without an actual disease) may also increase the risk of pain chronicity, disability and abstinence from physical activities (George et al. 2006). Because the causes or contributing factors of LBP are several and seldom caused by a single factor (Adam 2009), patients may hold different perceptions regarding the causes of their LBP (Sarah 2000). Therefore, it is important for healthcare providers to identify patients' perceptions regarding the causes of their LBP because this could help to clear the misconceptions they may hold regarding their pain and could also positively influence their choice of taking up a particular type of treatment (Darlow et al. 2014; Linton, Helsing \& Halden 1998).

\section{Relationship between knowledge, attitudes and beliefs}

A statistically significant relationship between knowledge, attitudes and beliefs was confirmed in our study. The knowledge, attitude and beliefs of patients regarding illness and pain are interrelated and inextricable (Bradley 1995). The author further alluded that it is difficult to make a distinction between knowledge and beliefs of the patient (Bradley 1995). Furthermore, Furinghetti and Pehkonen (2002) indicated that a belief is a prerequisite for knowledge and that there is a fine line between belief and knowledge. This implies that the knowledge of patients regarding their condition is linked with the beliefs they hold and their knowledge could influence these beliefs of their pain experience (Gbiri, Olawale \& Obi 2015).

\section{Conclusion}

This study highlighted that many patients with LBP in Malawi are not adequately knowledgeable about LBP and 
hold negative attitudes and beliefs regarding their LBP. Even though no differentiation was made between the knowledge, attitude and beliefs of patients living with chronic versus recurrent LBP, it can be concluded that providing education to the patients regarding their LBP and especially pain neuroscience education may enhance their knowledge regarding LBP. Therefore, LBP management approaches in Malawi should include education programmes aimed at empowering patients with knowledge regarding LBP, its contributing factors as well as changing their negative attitudes and beliefs about their pain. Patients' understanding of the cause and nature of their pain may enhance the achievement of treatment goals.

\section{Acknowledgements}

The authors would like to thank the study participants for without them the study would not have been possible, and the University of the Western Cape, Ethics committee in Malawi and hospital directors for approving the study.

\section{Competing interests}

The authors declare that they have no financial or personal relationships which may have inappropriately influenced them in writing this article.

\section{Authors' contributions}

N.S.T. conceptualised the study, designed the study, collected the data, analysed the data and wrote the first draft and subsequent revisions. I.D. was involved in the conceptualisation of the study, the study design and in editing the article.

\section{References}

Adam, S.R., 2009, 'Back pain and sciatica', Anaesthesia Analogy 85, 1066-1070.

Adams, M.A., 2004, 'Biomechanics of back pain', Acupuncture in Medicine 22(4), 178-188.

Allock, N., Elkan, R. \& Williams, J., 2007, 'Patients referred to pain management clinic: Beliefs, expectations and priorities', Journal of Advanced Nursing 60(3), 248-256. https://doi.org/10.1111/j.1365-2648.2007.04400.x

Bradley, C., 1995, 'Health beliefs and knowledge of patients and doctors in clinical practice and research', Patient Education and Counselling 26, 99-106. https://doi. org/10.1016/0738-3991(95)00725-F

Bruce, F., Walker, D.C., Reinhold, M. \& William, D.G., 2004, 'Low back pain in Australian adults' health provider utilization and care seeking', Journal of Manipulative and Physiological Therapeutics 27(5), 327-335. https://doi.org/10.1016/j. jmpt.2004.04.006

Cassidy, J.D.C., Cote, P.D.C., Carroll, L.J. \& Kristman, V., 2005, 'Incidence and course of low back pain episodes in the general population', Spine 24, 2817-2823.

Clarke, C.L., Ryan, C.G. \& Martin, D.J., 2011, 'Pain neurophysiology education for the management of individuals with chronic low back pain: A systematic review and meta-analysis', Manual Therapy 16(6), 544-549. https://doi.org/10.1016/j. math.2011.05.003

Cole, M.H. \& Grimshaw, P.N., 2003, 'Low back pain and lifting: A review of epidemiology and aetiology', Journal of Prevention, Assessment and Rehabilitation 21, 173-184.

Coudeyre, E., Tubach, F., Rannou, F., Baron, G., Coriat, F. \& Brin, S., 2007, 'Effect of a simple information booklet on pain persistence after an acute episode of low back pain: A non-randomized trial in a primary care setting', PLoS One 2(8), e706. https://doi.org/10.1371/journal.pone.0000706

Custer, R.L., Scarcella, J.A. \& Stewart, B.R., 1999, 'The modified Delphi technique: A rotational modification', Journal of Vocational and Technical Training 15(2), 1-10. https://doi.org/10.21061/jcte.v15i2.702

Darlow, B., Perry, M., Stanley, J., Mathieson, F., Melloh, M., Baxter, G.D. et al., 2014, 'Cross-sectional survey of attitudes and beliefs about back pain in New Zealand', BMJ Open 4(5), e004725. https://doi.org/10.1136/bmjopen-2013-004725
De Vos, A., 2002, Research at grass roots for the social sciences and human service professions, Van Schaik Publishers, Pretoria, South Africa.

Dupeyron, A., Ribinik, P., Gelis, A., Genty, M., Claus, D., Hérisson, C. et al., 2011, 'Education in the management of low back pain. Literature review and recall of key recommendations for practice', Annals of Physical and Rehabilitation Medicine 54(5), 319-335. https://doi.org/10.1016/j.rehab.2011.06.001

Foppar, I. \& Novack, R.H., 1996, 'The relation of self-reported back pain to psychosocial, behavioral, and health related factors in a working population in Switzerland', Social Science and Medicine 43(7), 1119-1126.

Foster, N.E., Pincus, T., Underwood, M., Vogel, S., Breen, A. \& Harding, G., 2003, 'Treatment and the process of care in musculoskeletal conditions: A multidisciplinary perspective and integration', Orthopedic Clinics of North America 34, 239-244.

Fowler, R.P. \& Dabco, D.C., 2004, 'Recommendations for management of uncomplicated back pain in the worker's compensation system. A focus on functional restoration', Journal of Chiropractic Medicine 3(4), 129-137. https:// doi.org/10.1016/S0899-3467(07)60100-1

Furinghetti, F. \& Pehkonen, E., 2002, 'Rethinking characterization of belief', in G. Leder, E. Pehkonen \& G. Torner (eds.), Beliefs: A hidden variable in mathematics education, pp. 39-57, Kluwer, Dordrecht.

Gbiri, C.A., Olawale, O.A. \& Obi, N.J., 2015, 'Associations between knowledge and beliefs of stroke and pathways to healthcare adopted by Nigerian stroke survivors', International Journal of Therapies and Rehabilitation Research 4(1), 35-42. https://doi.org/10.5455/ijtrr.00000046

George, S.Z., Wittmer, V.T., Fillingim, R.B. \& Robinson, M.E., 2006, 'Fear-avoidance beliefs and temporal summation of evoked thermal pain influence self-report of disability in patients with chronic low back pain', Journal of Occupational Rehabilitation 16(1), 95-108. https://doi.org/10.1007/s10926-005-9007-y

Ghaffari, M., Alipour, A., Jensen, I., Farshad, A.A. \& Vingard, E., 2006, 'Low back pain among Iranian industrial workers', Occupational Medicine 56, 455-460. https:// doi.org/10.1093/occmed/kql062

Hanney, W.J., Kolber, M.J. \& Beekhuizein, K.S., 2008, 'Implications for physical activity in the population with low back pain', American Journal of Lifestyle Medicine 3(1) 63-70. https://doi.org/10.1177/1559827608325627

Henrotin, Y.E., Cedrasch, C., Duplan, B., Bazil, T. \& Duquesnoy, B., 2006, 'Information and low back pain management: A systematic review', Spine 31(11), E326-E334. https://doi.org/10.1097/01.brs.0000217620.85893.32

Heymans, M.W., Van Buuren, S., Knol, D.L., Anema, J.R., Van Mechelen, W. \& De Vet, H.C.W., 2010, 'The prognosis of chronic low back pain is determined by changes in pain and disability in the initial period', Spine 10(10), 847-856. https://doi. org/10.1016/j.spinee.2010.06.005

Hoy, D., Bain, C., Williams, G., March, L., Brooks, P., Blyth, F.W. et al., 2012, 'A systematic review of the global prevalence of low back pain', Arthritis and Rheumatism 64(6), 2028-2037. https://doi.org/10.1002/art.34347

Hsu, C.C. \& Sandford, B.A., 2007, 'The Delphi technique: Making sense of consensus', Practical Assessment, Research and Evaluation 12(10), 1-7.

Jensen, M.P., Turner, J.A., Romano, J.M. \& Lawler, B.K., 1994, 'Relationship of painspecific beliefs to chronic pain adjustment', Pain 57, 301-309. https://doi. org/10.1016/0304-3959(94)90005-1

Kerr, M.S., Frank, J.W., Shannon, H.S., Norman, W.K., Wells, R.P., Neumann, W.P. et al. 2001, 'Biomechanical and psychosocial risk factors for low back pain at work', American Journal of Public Health 19(7), 1069-1075.

Koes, B.W., Van Tulder, M.W. \& Thomas, S., 2006, 'Diagnosis and treatment of low back pain', British Medical Journal 332, 1430-1434. https://doi.org/10.1136/ bmj.332.7555.1430

Maciel, S.C., Jennings, F., Jones, A. \& Natour, J., 2009, 'The development and validation of low back pain knowledge questionnaire-LKQ', Clinic 12, 1167-1175.

Manchikanti, L., Sigh, V., Falco, F.J., Benyamin, R.M. \& Hirsch, J.A., 2014, 'Epidemiology of low back pain in adults', Neuromodulation 17, 3-10. https://doi.org/10.1111/ ner.12018

Lee, C.M., Jeong, E.H. \& Freivalds, A., 2001, 'Biomechanical effects of wearing highheeled shoes', International Journal of Industrial Ergonomics 28, 321-326.

Linton, S.J., Helsing, A.L. \& Halden, K.A., 1998, 'Population based study of spinal pain among 35-45 year old individuals: Prevalence, sick leave and health care use', Spine 23, 1457-1463. https://doi.org/10.1097/00007632-199807010-00006

Linton, S.J., Vlaeyen, J. \& Ostelo, R., 2002, 'The back pain beliefs of health care providers: Are we fear-avoidant?', Journal of Occupational Rehabilitation 12, 223232. https://doi.org/10.1023/A:1020218422974

Louma, K., Riihimaki, H., Luukkonen, R., Raininko, R., Viikari-Juntura, E. \& Lamina, A., 2000, 'Low back pain in relation to lumbar disc degeneration', Spine 25, 487-492.

Louw, A., Diener, I., Butler, D.S. \& Puentedura, E.J., 2011, 'The effect of neuroscience education on pain, disability, anxiety, and stress in chronic musculoskeletal pain' Archives of Physical Medicine and Rehabilitation 92(12), 2041-2056.

Louw, A., Nijs, J. \& Puentedura, E.J., 2017, 'A clinical perspective on a pain neuroscience education approach to manualtherapy', Journal of Manual and Manupulative Therapy 25(3), 160-168. https://doi.org/10.1080/10669817.2017.1323699

Louw, Q.A., Morris, L.D. \& Grimmer, K.S., 2007, 'The prevalence of low back pain in Africa: A systematic review', BMC Musculoskeletal Disorders 8, 105. https://doi. org/10.1186/1471-2474-8-105

May, S., 2007, 'Patients' attitudes and beliefs about back pain and its management after physiotherapy for low back pain', Physiotherapy Research International 12(3), 123-135. https://doi.org/10.1002/pri.367 
Meeus, M., Nijs, J., Van Oosterwijck, J., Van Alsenoy, V. \& Truijen, S., 2010, 'Pain physiology education improves pain beliefs in patients with chronic fatigue syndrome compared with pacing and self-management education. A double blind

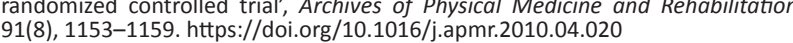

Mwilila, M.C., 2008, Work related low back pain among clinical nurses in Tanzania Unpublished master's thesis, Physiotherapy Department, University of the Western Cape.

Nasser, M.J., 2005, 'How to approach the problem of low back pain: An overview', Journal of Family Community Medicine 12(1), 3-9.

Ng'uurah, J.N. \& Frantz, J.M., 2006, 'Health education needs among individuals with low back pain', South African Journal of Physiotherapy 62(4), 22-27.

Okunribido, O.O., Magnusson, M. \& Pope, M.H., 2008, 'The role of whole body vibration, posture and manual materials handling as risk factors for low back pain in occupational drivers', Ergonomics 51(3), 308-329.

Pengel, L.H.M., Herbert, R.D., Maher, C.G. \& Refshauge, K.M., 2003, 'Acute low back pain: Systematic review of its prognosis', British Medical Journal 327, 323-327.

Pithwa, Y.K., 2011, Tips for back and neck care, viewed 10 September 2011, from http://www.spine-surgeon.org/tips.htm.

Ryan, C.G., Gray, H.G., Newton, M. \& Granat, M.H., 2010, 'Pain biology education and exercise classes compared to pain biology education alone for individuals with chronic low back pain: A pilot randomised controlled trial', Manipulative Therapy 15, 382-387. https://doi.org/10.1016/j.math.2010.03.003

Samad, I.A., Abdullah, H., Moin, S., Tamrin, B.M. \& Hashim, Z., 2010, 'Prevalence of low back pain and its risk factors among school teachers', American Journal of Applied Sciences 7(5), 634-639. https://doi.org/10.3844/ajassp.2010.634.639

Samanta, A. \& Beardsley, J., 1999, 'Low back pain: Which is the best way forward?', British Medical Journal 318, 1122-1123.

Sarah, K., 2000, Back sufferer's bible. You can treat your own back, Allenand and Unwin Publishers, Sydney, Australia.

Seotanto, A.L.F., Chung, J.W.Y. \& Wong, T.K.S., 2006, 'Are there gender difference in pain perception?', Journal of Neuroscience Nursing 38(3), 172-176. https://doi. org/10.1097/01376517-200606000-00006
Sikiru, L. \& Hanifa, S., 2010, 'Prevalence and risk factors of low back pain among nurses in a typical Nigerian hospital', African Health Sciences 10, 26-30.

Smedley, J., Egger, P., Cooper, C. \& Coggon, D., 1995, 'Manual handling activities and risk of low back pain in nurses', Occupational and Environmental Medicine 52(3), 160-163.

Soucy, I., Truchon, M. \& Cote, D., 2006, 'Work related factors contributing to chronic disability in low back pain', Work 26, 313-326.

Symonds, T.L., Burton, A.K., Tillotson, K.M. \& Main, C.J., 1996, 'Do attitudes and beliefs influence work loss due to low back trouble?', Occupational Medicine 46, 25-32. https://doi.org/10.1093/occmed/46.1.25

Tavafian, S.S., Eftekhar, H., Mohammad, K., Jamshidi, A.R., Assasi, N., Shojaeezadeh, D. et al., 2004, 'Patient's knowledge, perception and belief about the reasons of low back pain', Iranian Journal of Public Health 33(4), 57-60.

Tugwell, P.S., Santesso, N.A., O'Connor, A.M. \& Wilson, A.J., 2007, 'Knowledge translation for effective consumers', Physical Therapy 87(12), 1-12.

Udermann, B.E., Spratt, K.F., Donelson, R.G., Mayer, J., Graves, J.E. \& Tillotson, J., 2004 , 'Can a patient educational book change behavior and reduce pain in chronic low back pain patients?', Spine Journal 4, 425-435. https://doi.org/10.1016/j. spinee.2004.01.016

Vindigni, D. Bruce, F.W., Jamison, J.R., Costa, C.D., Parkinson, L. \& Blunden, S., 2005, 'Low back pain risk factors in a large rural Australian Aboriginal community. An opportunity for managing co-morbidities?', Chiropractic and Osteopathy 13, 21. https://doi.org/10.1186/1746-1340-13-21

Waddell, G., Feder, G. \& Lewis, M., 1997, 'Systematic reviews of bed rest and advice to stay active for acute low back pain', British Journal of General Practice 47 , 647-652.

WHO, 2004, Priority medicines for Europe and the world 'A public health approach to innovation': Background paper 6.24 low back pain, viewed 10 August 2017, from http://www.who.int/medicines/areas/priority medicines/BP6 2017, from

Yip, B.Y. \& Ho, S.C., 2001, 'Effects of socio-psychological stress on new and recurrent low back pain among Chinese community middle-aged women', Psychology, Health and Medicine 6(4), 362-372. 